\title{
EFFECT OF MOBILE PHONE USE ON BLINK RATE AMONG MBBS STUDENTS IN KATHMANDU
}

\author{
Mishal A, Giri U, Rizyal A
}

Department of Ophthalmology, Nepal Medical College Teaching Hospital, Attarkhel, Gokerneshwor-8, Kathmandu, Nepal

\begin{abstract}
Mobile devices such as smart phones and tablets are used globally for checking email, internet browsing, watching videos and posting on social media. A recent survey estimated that, by 2020 shipment of mobile phones will add up to 1.71 billion and a total of around 2.53 billion which constitutes almost one third of the world population owning a smart phone. According to American Optometric Association, 90\% of employees who use computers for at least three hours a day experience some vision problem. A reflex that closes and opens eyelids is known as blink, which helps in spreading tears over the conjunctiva and thereby keeping it moist. The normal blinking rate at rest is $17 \mathrm{blinks} / \mathrm{min}$, during conversation it increases to $26 \mathrm{blinks} / \mathrm{min}$, and it is as low as 4.5 blinks/min while reading. Prolong use of mobile phone affects the blink rate. A descriptive cross-sectional study was conducted among MBBS students at Nepal Medical College and Teaching Hospital to find out the effect of mobile device use on blink rate. The age of these students were from 19 to 26 year, with an average of 21.34 years. The result of this study shows that for male students, an average $3.8 \mathrm{hr} /$ per day use of mobile phone decreases the blink rate by $53.33 \%$ while watching videos and $80 \%$ while reading articles. Similarly, for female students, an average $3.5 \mathrm{hr} /$ per day use of mobile phone decreases the blink rate by $31.25 \%$ while watching videos and $62.50 \%$ while reading articles.
\end{abstract}

\section{KEYWORDS}

Blink rate, mobile phone, medical students, computer vision syndrome

\section{CORRESPONDING AUTHOR}

Optom. Anu Mishal

Optometrist,

Department of Ophthalmology,

Nepal Medical College and Teaching Hospital

Attarkhel, Gokarneshwor-8, Kathmandu, Nepal

Email: mishalanu44@gmail.com

Orcid ID: http://orcid.org/0000-0002-6125-267X

DOI: https://www.doi.org/10.3126/nmcj.v23i1.36220 


\section{INTRODUCTION}

Mobile devices such as smart phones or tablet have become ubiquitous. Nowadays, it is common for people to check e-mails, browse the internet, watch movies, post updates on social media, and read books on their portable devices. According to a recent survey, it was projected that worldwide smart phone shipments will add up to 1.71 billion in 2020, over a third of total world population owned a smart phone and there was an estimated total of around 2.53 billion smart phone users in the world. ${ }^{1}$ According to the American Optometric Association, $90 \%$ of people who use computers for at least three hours a day experience some vision problems. ${ }^{2}$ In Nepal on an average, over 6,581 new users are connected to the internet every day. ${ }^{3}$ The rate of visual disorders and ocular fatigue symptoms is common in visual display terminal users, and therefore optometrists have an important role in creating an awareness on these factors.

An involuntary act to close and open eyelids is known as blink which helps in proper spreading of tears over the conjunctiva and keeping it moist. A moist ocular surface and normal blinking is an essential requirement for normal vision. Mobile devices screen often increases burden on the human eyes. The normal blinking rate at rest is 17 blinks/ min, during conversation it increased to 26 blinks/min, and it is as low as 4.5 blinks/ min while reading. People tend to blink less than usual to adapt to this screen-saturated viewing situation. ${ }^{3}$ Since blinking is important for hydration of eyes, reduced blinking is considered one of the causes of dry eyes and Computer Vision Syndrome (CVS). CVS includes eye irritation, dry eye, red, itchy, and watery eyes; fatigue, including heaviness of the eyelids or forehead and difficulty in focusing the eyes. Headaches, neck aches, backaches and muscle spasms are also related symptoms of CVS.

Changes in the blink rate and pattern during mobile devices use may cause ocular discomfort symptoms triggered by a lack of adequate tear distribution. Ocular discomfort and visual fatigue were commonly reported in our outpatient department during performance of close tasks such as reading, particularly when electronic devices were employed.Studies have explored relationship between asthenopia and visual display terminals. Blinking rate has been found significantly reduced from 17/min during conversation to 6/min during mobile device use and reading in a study reported by Bhusharha. ${ }^{4}$ Since, no study on use of mobile phone and its effect on blink rate has been done in our country, this study was carried to find out the effect of mobile phones use on blink rate among young adults.

\section{MATERIALS AND METHODS}

This study was conducted at the Ophthalmology department of Nepal Medical College and Teaching Hospital among the $6^{\text {th }}$ semester, $3^{\text {rd }}$ year MBBS students who were posted in ophthalmology department from July 2019-October 2019. Ethical clearance was obtained from Research and Institutional Review Committee, Nepal Medical College and Teaching Hospital (NMC-IRC). Among a total of 120 students, only 64 students were selected as they did not have any ocular or systemic disorder. Students not willing to participate were excluded from the study. Informed and verbal consent of each participant was obtained before the study.

The selected students were requested to provide demographic data. Visual acuity was taken using Snellen's visual acuity drum at 6 meter of distance and at $33-40 \mathrm{~cm}$ using near visual acuity chart for far and near vision respectively. Retinoscopy was performed by Heine's Streak Retinoscope for objective refraction. Subjective refraction was done to access any kind of subjective acceptance of refractive correction. Anterior segment and posterior segment was examined under Haag Streit slit lamp to rule out presence of any ocular abnormalities.

\section{Blinking rate was measured in following three ways.}

1. Number of blinks of the participant was counted while talking to examiner and noted.

2. Number of blinks of the participant was counted while reading an article on mobile phone and noted.

3. Number of blinks of the participant was counted while watching a video on mobile phone and noted.

For all the three cases duration was 1 min each. In the first test, the participants were allowed to talk with the examiner for 1 minute and the number of blinks was counted and recorded. In the second test, the same participants were allowed to read an article from their smartphone for 1 minute and the number of blinks were counted and recorded.

In the third test, the same participants were allowed to watch a video in their mobile phone for 1 minute and the number of blinks were counted and recorded. 
Data was entered in MS Excel and analysis was done on SPSS version-16. Association between duration of mobile use and blink rate were determined using chi- square test. $\mathrm{P}$ value of less than 0.05 was considered to be significant.

\section{RESULTS}

A total of 64 medical students participated in this study among which 25 were males and 39 were females comprising $39.1 \%$ and $60.9 \%$ respectively. The age of these students was between 19 to 26 years (Table 1 ), with an average of 21.34 years. Majority of the participants were female in the age group 19-22 years comprising $52.1 \%$.

\begin{tabular}{|lcccc|}
\multicolumn{4}{c}{ Table 1: Demographic profile of } \\
participants
\end{tabular}

while watching video and 3 and 6 times per min while reading an article on mobile phone. The average duration of mobile phone use was found 3.8 and 3.5 hours per day for male and female respectively.

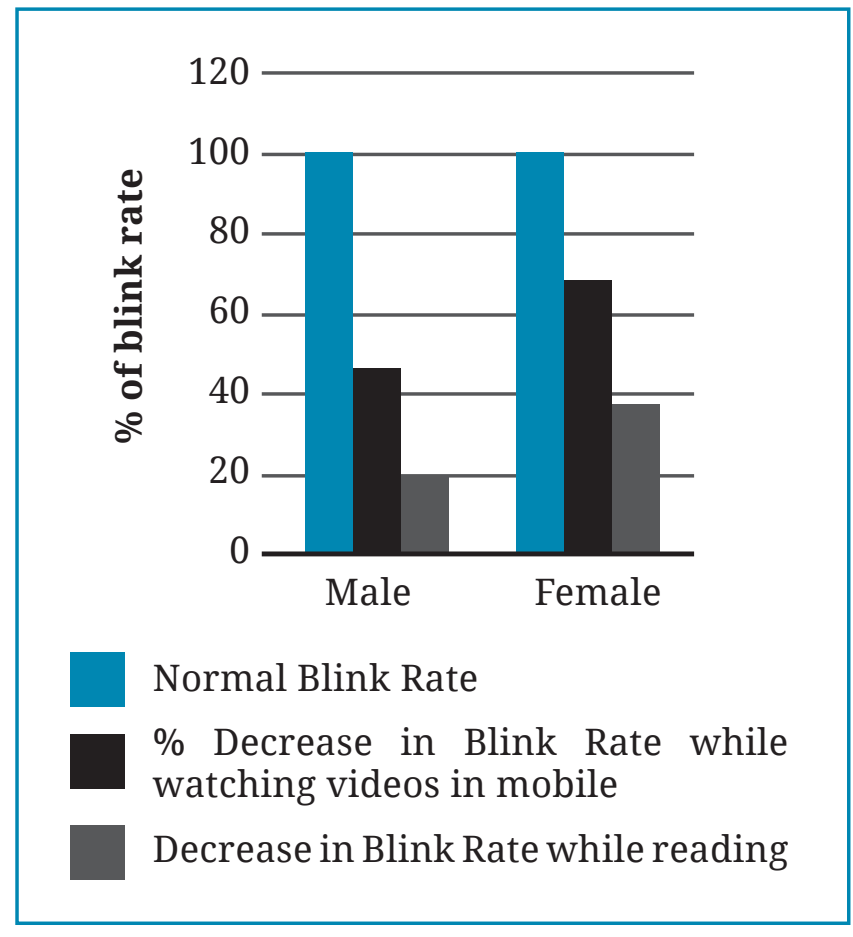

Fig. 1: Decrease in Blink Rate

\begin{tabular}{|lcccc|}
\hline & $\begin{array}{c}\text { Table 2: Frequency of blink rate } \\
\text { Average normal } \\
\text { blink rate } \\
\text { (times/min) }\end{array}$ & $\begin{array}{c}\text { Average blink rate } \\
\text { while watching } \\
\text { video (times/min) }\end{array}$ & $\begin{array}{c}\text { Average blink } \\
\text { rate while reading } \\
\text { (times/min) }\end{array}$ & $\begin{array}{c}\text { Average use of } \\
\text { mobile phone } \\
\text { (hr/day) }\end{array}$ \\
\hline Male & 15 & $7(46.67 \%)$ & $3(20.0 \%)$ & 3.8 \\
Female & 16 & $11(68.75 \%)$ & $6(37.5 \%)$ & 3.5 \\
\hline
\end{tabular}

\begin{tabular}{|lcc|}
\hline \multicolumn{3}{|c|}{ Table 3: Percentage of decrease in blink } \\
rate \\
\hline $\begin{array}{c}\text { While watching } \\
\text { video }\end{array}$ & While reading \\
\hline Male & $53.33 \%$ & $80.0 \%$ \\
Female & $31.25 \%$ & $62.5 \%$ \\
\hline
\end{tabular}

Table 2 shows the frequency of blink rate. The average normal blinking rate was 15 and 16 times per minute of male and female respectively followed by 7 and 11 times/min
Table-3 reveals that there was a drastic decrease in blink rate while watching a video on the mobile showing reduction about 53.33\% and $31.25 \%$ in males and females respectively and reduction was about $80 \%$ and $62.5 \%$ while reading an article for male and female respectively.

Thus, this study shows that the decrease in blink rate was more while reading an article than while watching a video.

Table-4 shows the reduction in blink rate according to increase in mobile use. It was seen that the more the number of hours spent on the mobile phone/day, the less was the blink 
Table 4: Average blink rate according to use of mobile devices

\begin{tabular}{|ccc|}
\hline $\begin{array}{c}\text { Average use of mobile phones / } \\
\text { day }\end{array}$ & $\begin{array}{c}\text { Average normal blink } \\
\text { rate (times/min) }\end{array}$ & P-Value \\
\hline 2 hr & 16.33 & 0.005 \\
$2-4 \mathrm{hr}$ & 14.5 & \\
$4-6 \mathrm{hr}$ & 14.3 & P-Value \\
\hline Average use of mobile phones / & $\begin{array}{c}\text { Average blink rate } \\
\text { while watching video } \\
\text { (times/min) }\end{array}$ & \\
\hline$\geq 2 \mathrm{hr}$ & 15.67 & 0.02 \\
$2-4 \mathrm{hr}$ & 8.83 & \\
$4-6 \mathrm{hr}$ & 6.62 & P-Value \\
\hline Average use of mobile phones / & $\begin{array}{c}\text { Average blink rate } \\
\text { while reading (times/ } \\
\text { min) }\end{array}$ & \\
\hline $2 \mathrm{hr}$ & 11.33 & 0.07 \\
\hline $2-4 \mathrm{hr}$ & 4.25 & \\
$4-6 \mathrm{hr}$ & 4.2 & \\
\hline
\end{tabular}

rate. This was statically significant. There was a similar result with the average number $2 \mathrm{hrs} /$ day on the phone and the blink rate while seeing a video on the mobile phone. However, there was no statistical significance between number of hrs/day and the blink rate while reading an article on the phone.

\section{DISCUSSION}

Mobile phone use is a global habit today. A study done by Shrestha, ${ }^{5}$ on visual problems among visual display terminal users among patients in Kathmandu showed that among 76 patients, ocular abnormalities were seen in $92.1 \%$. A study by Seongwon, ${ }^{2}$ reported that the average human eye blink rate is 22.4-8.9 times per minute under relaxed condition. However, it decreases to 10.5-6.5 times per minute while reading a book and 7.6-6.7 times per minute while doing near work such as using the computer. This was similar to our study where normal blink rate was 15-16 times/min and 7-11times/min while watching video on mobile phone and 3-6 times/min while reading an article on mobile.

Ram and Mojumder, ${ }^{1}$ mentioned in their study that prolonged activity on smart phone before sleep leads to convergence changes by showing eye strain and fatigue.
A review article on Computer Vision Syndrome reported by Kokab ${ }^{6}$ showed that the blinking reflex is generally slower when concentrating on a single task. During computer works the eyes are kept wide open and constantly focus on single source and also the blinking reflex drops and there is increase in evaporation of tears due to wide opening of eyes. This is one of the factors in development of computer vision syndrome. Our study showed that blinking rate decreases while using mobile phones and the relation between decrease in blink rate and mobile phone use per hour is directly proportional.

A cross-sectional study by Sultan ${ }^{14}$ on Computer Vision Syndrome prevalence, knowledge and associated factors among Saudi Arabia University Students showed $62.14 \%$ presented with eye strain while the second common symptom was burning sensation in eyes complained by $7.57 \%$ of the patients which is similar to other studies where eye strain was most common.

Other similar studies revealed that a significant reduction in blink rate occurs during mobile phone use. Similarly, this research also shows blink rate reduces from $15.5 / \mathrm{min}$ to $9 / \mathrm{min}$ while watching video and $4.5 / \mathrm{min}$ while reading text in mobile. 
Computer Vision Syndrome, also referred to as digital eye strain, describes a group of eye and vision-related problems that result from prolonged computer, tablet, e-reader and cell phone use. Many individuals experience eye discomfort and vision problems when viewing digital screens for extended periods. It is advisable to prevent prolong working hours and maintaining time break during activity with mobile devices can cause less damage to ocular health.
In conclusion, this study showed that there was a decrease in blink rate during mobile phone use while reading an article or watching a video. Therefore it is advisable to reduce the amount of digital eye strain, 20-20-20 therapy is suggested that is taking a 20 second break every 20 minutes by looking 20 feet away ${ }^{15}$.

\section{ACKNOWLEDGEMENT}

The authors are thankful to the $\mathrm{VI}^{\text {th }}$ semester students who participated in the study.

\section{REFERENCES}

1. Male S R, Majumder C. Effect of Smartphone activity over convergence insufficiency score before sleep. J Peer Sci 2018; 1: 1-4.

2. Han S, Sungwon Y, Kim J and Gerl A. Framework of Eye Tracking and Blink Detection for Mobile Device Users. Res Gate 2012; 6: 1-6.

3. Dhungana S. Internet penetration at $61 \mathrm{pc}$ of population. The Himalayan times.2017

4. Abusharha A. Changes in blink rate and ocular symptoms during different reading tasks. Clin Optom (Auckl) 2017; 9: 133-138.

5. Shrestha G S, Mohamed F and Narayan S. Visual problems among video display terminals in Nepal. J Optom 2011; 4: 56-62.

6. Kokab S, Khan M. Computer vision syndrome review article. Surv Ophthalmol 2005; 50: 253-62.

7. Venkatesh S, Girish A, Shashikala, Kulkarni P, Mannava S, RajarathnamR. A Study of computer vision syndrome at the Workplace - prevalence and causative factors. Int'l J Contemp Med Res 2016; 3: 2375-77.

8. Awrajaw D, Adane F, Nega A, Dabawami S, and Haile D. Computer vision syndrome and associated factors among computer users in Debre Tabor Town. J Environ Pub Health 2018; 2: $1-8$.
9. Hyung J, Kim K and Moon N. Smartphone use is a risk factor for pediatric dry eye disease according to region and age: a case control study. BMC Ophthalmol 2016; 16: 188.

10. Rosenfield M. Computer vision syndrome(a.k.adigital eye strain). Optom in Pract 2016; 17: 1 10.

11. Himebaugh NL, Begley CG, Bradley A, Wilkinson JA. Blinking and tear break-up during four visual tasks. Optom Vis Sci 2009; 86: 106-14.

12. Bentivoglio AR, Bressman SB, Cassetta E, Carretta $\mathrm{D}$, Tonali P, Albanese A. Analysis of blink rate patterns in normal subjects. Mov Disord 1997; 12: 1028-34.

13. Takenori I, Iwagami M, Hiratsuka Y, Keiichi F, Okumura Y, Shiang T. Maximum blink interval is associated with tear film breakup time: A new simple, screening test for dry eye disease. Sci Rep 2018; 8: 31814-7.

14. Sultan H, Rashidi A and Alhumaidan H. Computer vision syndrome prevalence, knowledge and associated factors among Saudi Arabia University Students: Is it a serious problem? Int'l J Health Sci (Qassim) 2017; 11: 17-19.

15. Brian C. Deconstructing the 20-20-20 Rule for digital eye strain: Optometry Times 2018 Feb 22. 